\title{
Corrosion Protection of AA7075 Aluminium Alloy by Trimethoxy-Silanes Self-Assembled Monolayers
}

\author{
Rodrigo S. Neves, ${ }^{1}$ Daiane P. B. Silva, ${ }^{2}$ and Artur J. Motheo ${ }^{3}$ \\ ${ }^{1}$ Materials Metrology Division (Dimat), National Institute of Metrology, Quality and Technology (Inmetro), \\ 25250-020 Duque de Caxias, RJ, Brazil \\ ${ }^{2}$ Department of Chemistry, Federal University of São Carlos (UFSCar), 13565-905 São Carlos, SP, Brazil \\ ${ }^{3}$ Laboratory of Interfacial Electrochemistry, Department of Physical Chemistry, Institute of Chemistry of São Carlos (IQSC), \\ University of São Paulo (USP), 13560-970 São Carlos, SP, Brazil
}

Correspondence should be addressed to Rodrigo S. Neves; rodrigo_santis_neves@yahoo.com.br

Received 31 January 2013; Accepted 28 February 2013

Academic Editors: A. I. Bhatt, A. C. Chialvo, A. Guerrieri, and A. A. Moya

Copyright (C) 2013 Rodrigo S. Neves et al. This is an open access article distributed under the Creative Commons Attribution License, which permits unrestricted use, distribution, and reproduction in any medium, provided the original work is properly cited.

This study presents electrochemical data concerning the aluminium alloy AA7075 surface modified by self-assembled monolayers (SAMs) of octadecyl-trimethoxy-silane and propyl-trimethoxy-silane. Polarisation curves have shown SAMs blocking effect, as they partially block the oxygen reduction reaction and displace the corrosion potential to positive values. Electrochemical impedance spectroscopy experiments have suggested that the protective effect comes from the oxide layer stabilization by the organic monolayers, which block the corroding species diffusion to the surface. These results show the potential of using methoxysilanes SAMs as corrosion protective coatings; however, they are also indicative of the superior octadecyl-trimethoxy-silane protective characteristics.

\section{Introduction}

The corrosion protection of aluminium alloys is a very important topic in the electrochemistry and engineering fields, since these materials are used in different industrial areas and undergo localized corrosion $[1,2]$. As an example, about a decade ago the US Air Force had showed interest in the development of aluminium alloys protective coatings with at least 30 years lifetime before maintenance [3].

In this context, much attention has been dedicated to the AA7075 alloy corrosion behavior [4-10], since this material is extensively used in aerospace and military industry due to its good mechanical performance and low density. In order to improve the aluminium mechanical properties, this alloy contains zinc (5.1-6.1 wt\%), copper (1.2-2.0 wt\%), and magnesium (2.1-2.9 wt\%) as its main alloying components. The presence of such allowing elements results in the formation of intermetallic particles during the casting and homogenization processes. From an electrochemical standpoint, copper and zinc rich intermetallics are cathodic to the aluminium matrix, hence promoting the dissolution of aluminium, while the magnesium rich ones are anodic to the matrix and undergo dissolution [11]. This mechanism favours the occurrence of localized corrosion processes, hence making the development of specific corrosion protection technologies a subject of continuous interest.

In the scope of new corrosion protection methods for aluminium alloys, the interest in the electrochemical properties of such materials modified with self-assembled monolayers (SAMs) has grown in the recent years [12-14]. This interest is a consequence of the potential application of SAMs as corrosion protective coatings as a substitute for the typical chromium conversion coatings [13-15], which are good protective coatings; however, the toxic nature of the chromium coating baths is an issue of serious environmental concerns.

The term SAM refers to molecular monolayers that strongly bind to a surface and go through a spontaneous self-organization process. The molecules used to provide an SAM have three main characteristics: (i) a functional group 
which chemically binds to the surface, responsible for the layer adhesion to the substrate (head group) and specific for different substrates; (ii) an aliphatic chain, which acts on the self-organization process; (iii) a functional group exposed on top of the layer (tail group) [16-18]. The condensation of SAMs is a widely used surface modification technique, mainly because of its flexibility to combine specific binding groups for particular substrates with selected functional groups exposed on top of the monolayer. These features make SAMs a suitable choice to produce surface modifications for several industrial applications [19].

Several studies have shown SAMs corrosion protection capabilities on different metals, such as copper [20-27], iron [28-30], pure aluminium [12,31], and some aluminium alloys $[13,14,27,32-35]$. When acting as protective coatings, SAMs are physical barriers that block the access of the corroding species to the protected surface, with their protective efficiency particularly related to the aliphatic chain length and to the nature of the tail group.

Studies on the influence of the chain size in the behaviour of SAM films have shown that the use of long chain molecules maximizes the coating lifetime and the protective efficiency, probably due to the condensation of more compact and crystalline monolayers [21-23]. Other studies, considering SAMs with similar aliphatic chain lengths, have demonstrated that the tail group can be optimized in different ways. The use of hydrophobic groups favours the corrosion protection properties by improving the barrier effect, but once the corrosion starts, the film quickly collapses. Notwithstanding, the use of hydrophilic groups $(\mathrm{OH}$ and $\mathrm{COOH})$ on the tail position diminishes the blocking efficiency, but when corrosion starts the adsorbed molecules change the orientation at the surface and the corrosion protection is improved [36].

In addition to the natural blocking effect, SAMs may also be used as primers, in order to promote or improve the adhesion of a second coating [37-39] and to provide additional protection [40, 41]. In this specific case the tail group can be optimized to promote adhesion via physical interaction or chemical bonding, as in the case of grafting polymerization $[39,42,43]$. The possibility of a double function coating is an additional appeal in developing corrosion protective coatings based on SAMs.

SAM condensation over aluminium-based substrates depends on the use of molecules that strongly bind to the oxide layer that naturally covers the alloys surface. Recent studies on SAMs condensation over aluminium surfaces [44] have shown that methoxy-silane monolayers, specifically the octadecyl-trimethoxy-silane (ODTMS) and propyltrimethoxy-silane (PTMS), may be suitable choices for corrosion protection of aluminium-based materials, since these molecules form compact and uniform coatings over oxide surfaces with industrial quality finishing in short substrate exposition times.

When considering technological applications, besides the short condensation times, the simplicity of the surface modification procedure is another aspect to be valued. In this aspect, while PTMS and ODTMS are used in aqueous/alcoholic solutions in a $\mathrm{pH}$ range where the aluminium oxide surface is stable, different organosilane molecules need certain special conditions for the monolayer condensation. For example, the use of chlorosilanes to obtain SAMs demands the use of water free solutions to avoid hydrochloric acid production during the hydrolysis $[45,46]$, while perfluoroalkyl silane SAM condensation from dipping solutions results in disordered monolayers [47]. By the way, the short condensation times, the method simplicity, and the ODTMS and PTMS SAMs stability over aluminium-based surfaces are major advantages in the case of possible industrial applications, which make them a promising corrosion protective coating to aluminium alloys.

In this context, the aim of the present study is to evaluate the electrochemical characteristics of the AA7075 aluminium alloy modified with ODTMS and PTMS SAMs, in contact with a sodium chloride aqueous solution corroding media, based on polarization curves and electrochemical impedance spectroscopy (EIS) measurements.

\section{Materials and Methods}

2.1. Substrate Preparation. Before the SAM condensation on the surface, each alloy sample $\left(1.78 \mathrm{~cm}^{2}\right)$ was manually abraded using emery paper up to P1200 grade, constantly washing with water (MilliQ-UV purified water was used in all procedures), obtaining a regular distribution of scratches. The samples were then washed in water, immersed in a glacial acetic acid solution ( $\mathrm{pH} 3$ ) for one hour, using a sonic bath, and dried in air. This procedure was successfully applied in several works of organosilanes SAMs condensation over oxide layers and is known to result in well reproducible surfaces [44, 48-53]. This preparation method results in relatively heterogeneous and rough surfaces, equivalent to the finishing of aluminium used for industrial applications. Under these conditions the macroscopic characteristics of the surface directly affect the structure of the SAM formed onto the substrate [44]. The samples prepared by this method and not covered by any SAM will be referred to as bare samples for the remaining of the text.

2.2. Surface Modification. ODTMS (Fluka 90\%) and PTMS (Fluka 97\%) were used for SAMs preparation without further purification. In the condensation process, the substrate was immersed in a solution composed of organosilane $0.75 \%$ $\mathrm{v} / \mathrm{v}$ in 1:9 water: ethanol mixture. Before the substrate immersion, the $\mathrm{pH}$ of the dipping solution was adjusted to 4 with the addition of some glacial acetic acid drops and the solution was stirred for 10 minutes to ensure the complete organosilane hydrolysis. The samples were immersed in the dipping solution for 10 minutes and dried with nitrogen. This procedure is the same used by Thomsen et al. [44] and it is known to result in very uniform ODTMS and PTMS SAMs over aluminium oxide surfaces.

2.3. Electrochemical Experiments and Images Acquisition. The electrochemical experiments were performed in a single compartment electrochemical cell, using a platinum sheet $\left(2.5 \mathrm{~cm}^{-2}\right)$ as counter electrode and a saturated calomel electrode (SCE) as reference, in a $\mathrm{NaCl}$ (Synth) $0.6 \mathrm{~mol} \mathrm{dm}^{-3}$ 
working solution. The working electrodes were AA7075 alloys samples submitted to the different surface modification methods (with the area exposed to the working solution limited to $1.13 \mathrm{~cm}^{-2}$ ). All the electrochemical experiments were performed using an Autolab potentiostat model PGSTAT 20 (ECHOCHIMIE), equipped with a frequency response analyzer (FRA) module. All the electrochemical experiments were performed at $25 \pm 2^{\circ} \mathrm{C}$ without deaeration.

The potentiodynamic polarization curves were obtained in a potential range of -0.3 to $1.3 \mathrm{~V}$ versus SCE, with a sweep rate of $0.5 \mathrm{mV} \mathrm{s}^{-1}$.

The EIS measurements were performed at an underpotential value of $-50 \mathrm{mV}$ for the bare sample and at the mean potential between the values of $E_{\text {corr }}$, determined from the polarization curves, for the bare sample and for each one of the coated samples. The results have shown that at this potential value the coatings effectively protect the surface; therefore it is a suitable choice for the EIS studies. Frequencies from $0.1 \mathrm{~Hz}$ to $10 \mathrm{kHz}$ were used with ten points per frequency decade and the alternate sign amplitude was $5 \mathrm{mV} \mathrm{rms}$. In order to translate the EIS results to interface physical-chemical models, equivalent electrical circuits were fitted to the EIS results using the EQUIVCRT program, developed by Boukamp [54]. In the fitting procedure only fit quality parameter $\left(\chi^{2}\right)$ values on the magnitude order of $10^{-4}$ or less were accepted.

The optical images presented on this paper were obtained using a conventional digital camera and the scanning electron microscopy (SEM) images were realised in a Zeiss-Leica microscopy, model DSM 960, with electrons beam operating between 15 and $20 \mathrm{kV}$.

\section{Results and Discussion}

The polarization curves for the AA7075 surfaces modified by the different treatments, in contact with the working solution, are shown in Figure 1. The corrosion potential $\left(E_{\text {corr }}\right)$ and pitting corrosion potential $\left(E_{\text {pit }}\right)$ values, obtained from the different curves, are shown in Table 1.

The bare substrate exhibits $E_{\text {corr }}=-0.85 \mathrm{~V}$ and $E_{\text {pit }}=$ $0.79 \mathrm{~V}$, while the coated samples show a displacement of both characteristic potentials to be more positive values (more noble potentials). In the case of $E_{\text {corr }}$, while this displacement is c.a. $+20 \mathrm{mV}$ for the PTMS coated sample, it is about $+130 \mathrm{mV}$ for the ODTMS coated sample, both values compared to the bare surface. It is also possible to observe that corrosion current density decreases for the coated samples when compared to the bare surface (see Table 1), which confirms the corrosion protection behaviour for both coatings.

The SAMs coatings also affect the oxygen reduction reaction (ORR), as observed at the cathodic branch of the polarization curves, since both SAMs diminish the current levels associated to ORR by almost one order of magnitude. This behaviour is different from that observed by Hintze and Calle [13] on the AA2024 alloy corrosion protection by ethoxy-silanes SAMs, where the ORR is not affected by the coating. These results show that ODTMS and PTMS coatings

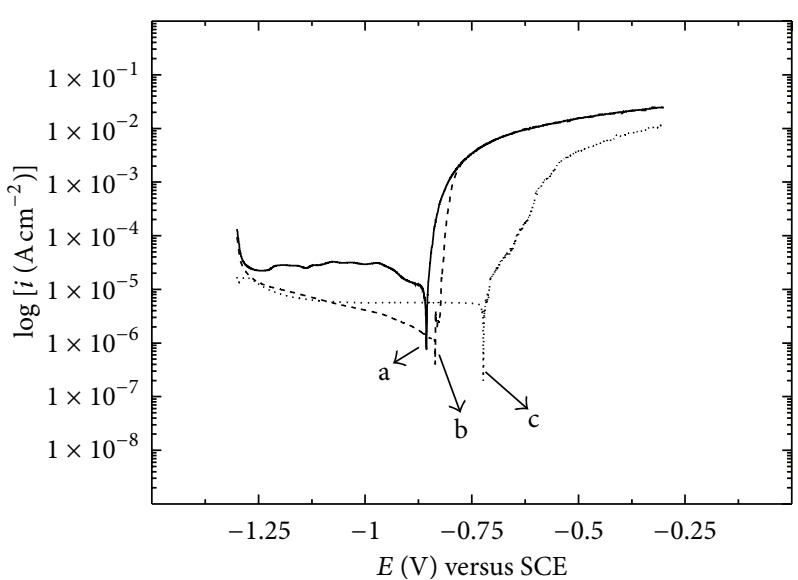

FIGURE 1: Polarization curves for the AA7075 samples submitted to different surface modifications: (a) bare surface, (b) modified with PTMS coating, (c) modified with ODTMS coating.

TABLE 1: Polarisation curves parameters for Figure 1.

\begin{tabular}{lcccc}
\hline Sample & $\begin{array}{c}E_{\text {corr }} \\
(\mathrm{V} / \mathrm{SCE})\end{array}$ & $\begin{array}{c}I_{\text {corr }} \\
\left(\mathrm{mA} / \mathrm{cm}^{2}\right)\end{array}$ & $E_{\text {pit }}(\mathrm{V} / \mathrm{SCE})$ & $\begin{array}{c}\text { Corrosion rate } \\
(\mathrm{mm} / \text { year })\end{array}$ \\
\hline \multicolumn{5}{c}{ AA7075 } \\
Bare & -0.85 & 9.37 & -0.79 & $9.9 \times 10^{-2}$ \\
PTMS & -0.83 & 1.04 & -0.77 & $1.2 \times 10^{-2}$ \\
ODTMS & -0.72 & 3.10 & -0.60 & $3.0 \times 10^{-2}$ \\
\hline
\end{tabular}

avoid some of the oxygen molecules present in the solution to reach the surface, partially suppressing the ORR. Similar behaviour was also observed on iron corrosion protection by alkanethiols SAMs [28, 29].

Despite the fact that the monolayer compactness and homogeneity correct analysis is impractical due to the primary surface roughness, the effect on the ORR should be directly related to the coating compactness. In the case of siloxanes SAMs, it is strongly associated to the homogeneity of the oxide layer that covers the alloy surface and works as the substrate for the SAM condensation. Such aspects suggest that the combination of surface pretreatments that result in compact and homogeneous oxide layers, with closed packed and homogeneous SAMs, is necessary to improve corrosion protection.

Considering the anodic branch of the polarization curve, it is possible to observe that ODTMS coatings also affect the $E_{\text {pit }}$ values, whilst PTMS coatings do not change the shape of the polarization curve anodic branch. In this aspect, the ODTMS layer displaces the $E_{\text {pit }}$ to more noble potentials, approximately $+190 \mathrm{mV}$, and slightly decreases the current level associated to the process. This behaviour suggests the ODTMS coatings high stability at higher overpotentials.

The coatings protective character can be easily confirmed by the surface optical and SEM images, registered after the polarization, shown in Figure 2. In the optical images with no magnification, the bare sample clearly presents corrosion pits uniformly distributed over the entire surface, while PTMS coated sample shows a less intense surface attack and, for 

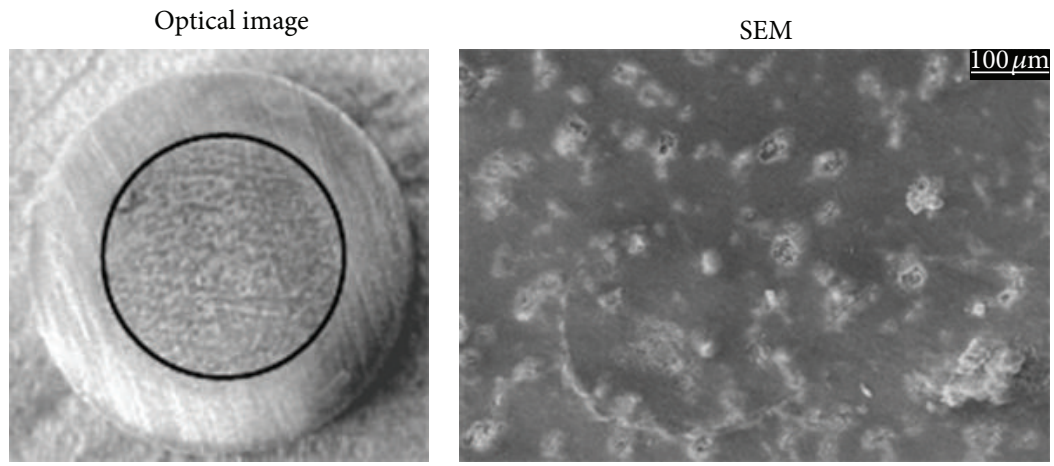

(a)
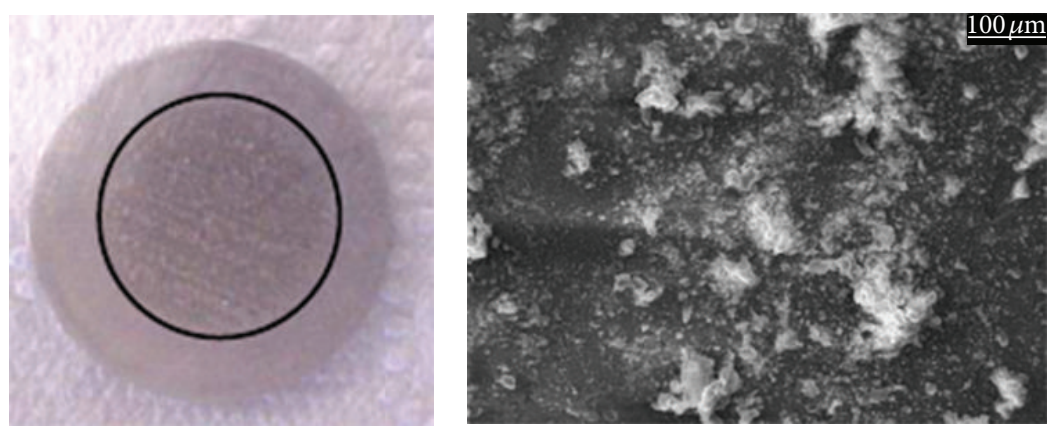

(b)
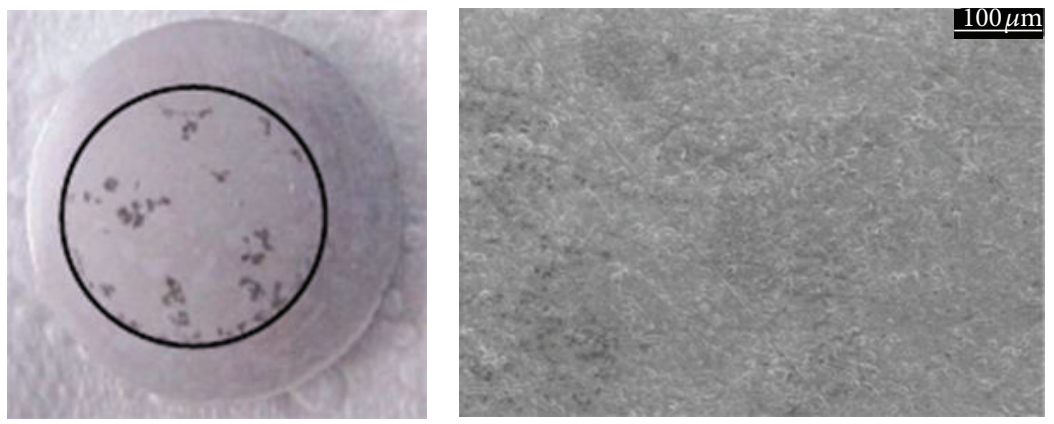

(c)

FIGURE 2: Photographs (no magnification) and SEM (500x magnification) images of the AA7075 samples submitted to different surface modifications, after the polarization: (a) bare surface, (b) modified with PTMS coating, (c) modified with ODTMS coating. The black circle shows the area exposed to the corrosion media $\left(1.13 \mathrm{~cm}^{2}\right)$.

the ODTMS coating, the corrosion is almost suppressed over the entire surface. This behaviour can be observed with details in the SEM images. In this case it is possible to see the pits distribution for the bare surface, the corroded areas progressive diminution for the PTMS, and the suppression of pitting corrosion for the ODTMS coated samples.

Based on these images and on SAM coatings nature, it is possible to consider that the attack to the surface takes place in the protective films defects, which are common in SAMs and may also be related to defects in the natural oxide layer. In this aspect, the results suggest that ODTMS coatings present fewer defects when compared to the PTMS ones, mainly at high overpotentials, where pit corrosion takes place. However, the current density and corrosion rate values (Table 1) indicate that both coated samples are electrochemically equivalent at low overpotentials, near $E_{\text {corr }}$.

The electrochemical characteristics of the coated samples were also studied by EIS experiments in the potential region where SAMs effectively inhibit the corrosion reactions, as described in Section 2.

The Nyquist plots for the bare and coated samples are shown in Figure 3. The diagrams corresponding to the different samples are similar in shape, presenting different capacitive processes in specific frequency regions. There are also strong indications of diffusion-controlled processes for the coated surfaces, observed in the low frequency region. The $Z^{\prime}$ values comparison for the different samples to the results observed in the polarization curves are coherent, since 


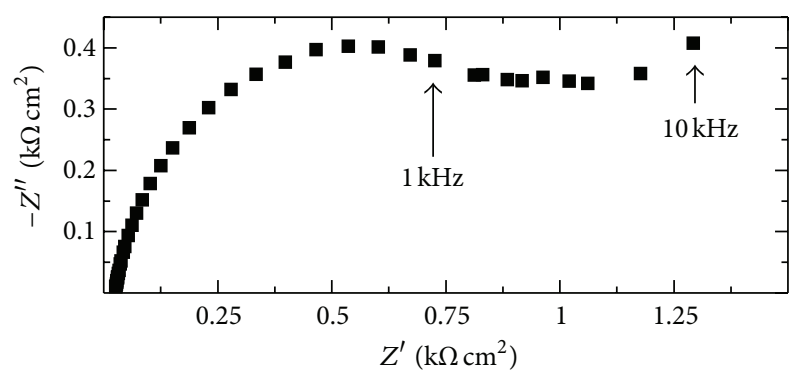

(a)

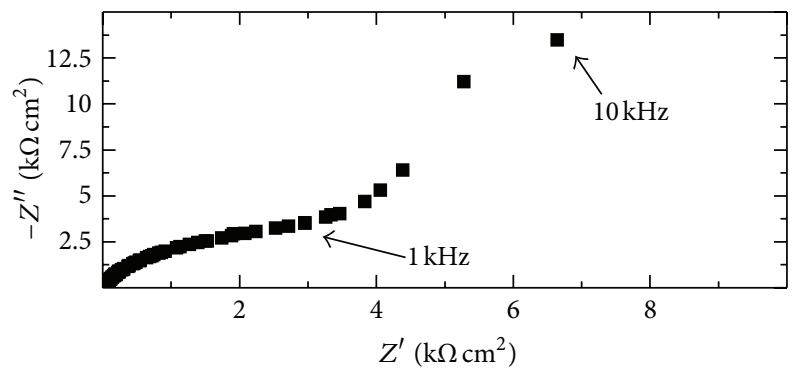

(b)

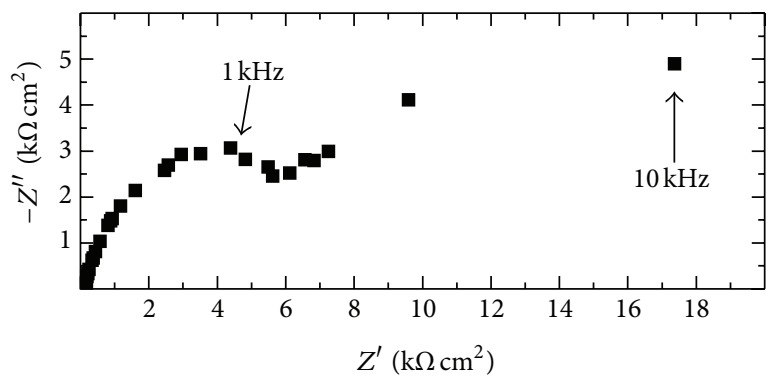

(c)

FIgURE 3: Nyquist plots of the AA7075 samples submitted to different surface modifications: (a) bare surface, (b) modified with PTMS coating, (c) modified with ODTMS coating.

the higher values of $Z^{\prime}$ are observed for ODTMS coatings, followed by the PTMS and the bare surface, respectively, confirming the higher ODTMS SAM corrosion protection effectiveness.

The total impedance and the phase angle dependence on the frequency (Bode plots) for the different samples are shown in Figure 4. The $\log |Z|$ versus $\log f$ plot (Figure 4(a)) clearly shows that both coatings increase the total system impedance. In the low frequency region, this augment is about one order of magnitude and clearly shows the corrosion resistance improvement.

The SAM coatings also affect the phase angle dependence on the frequency, as observed in Figure 4(b). For the coated samples, the capacitive frequency domain changes to lower frequency regions when compared to the bare surface and, specifically for the ODTMS, the maximum phase angle value decreases due to the higher capacitance dispersion and to the impedance associated to the corroding species diffusion through the SAM.

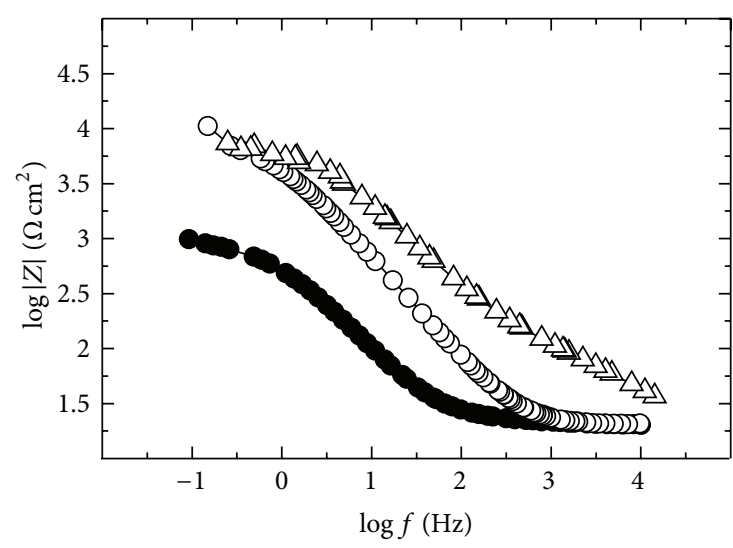

(a)

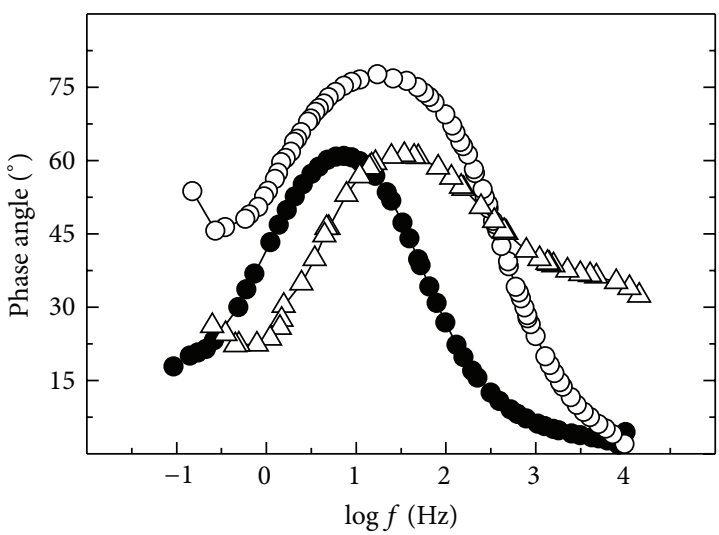

(b)

FIGURE 4: Bode plots of the AA7075 samples submitted to different surface modifications, (a) dependence of $\log (Z)$ on $\log (f)$, (b) dependence of phase angle on $\log (f)$. $\circ$ bare surface; $\bullet$ PTMS coating; $\triangle$ ODTMS coating.

In order to improve the EIS results analysis, fitting of equivalent electrical circuits to the EIS results is a good strategy to develop the physicochemical models for the interfaces exhibiting corrosion processes [55-57].

The model fitted to the bare sample, which is covered only by a natural oxide layer, is a simple equivalent circuit developed by Jüttner [56] to model the corrosion of heterogeneous surfaces (Figure 5(a)). In this model $R_{s}$ is a resistance related to the electrolyte solution conductivity, $\mathrm{CPE}_{\mathrm{DL}}$ is a constant phase element (CPE) related to the electrical double layer (DL) capacitance, $R_{\mathrm{ct}}$ is the resistance associated to the corrosion process, $R_{f}$ is the oxide layer associated resistance, and $\mathrm{CPE}_{f}$ is a CPE associated to the oxide film capacitance.

The CPE is a circuit element normally used to deal with nontrivial capacitance dependence on the frequency (capacitance dispersion), $[58,59]$ and its impedance is expressed by:

$$
Z_{\mathrm{CPE}}(\omega)=\frac{1}{Y_{0}(i \omega)^{n}},
$$

where $Y_{0}$ is the preexponential parameter of the $\mathrm{CPE}$, directly proportional to the capacitance of a conventional capacitor, the exponent $n$ is a parameter with values between 0 and 


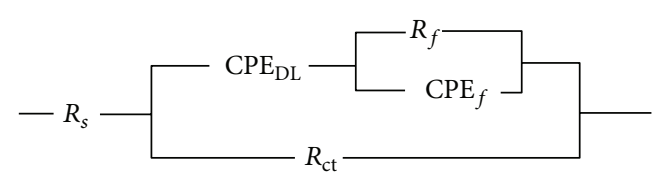

(a)

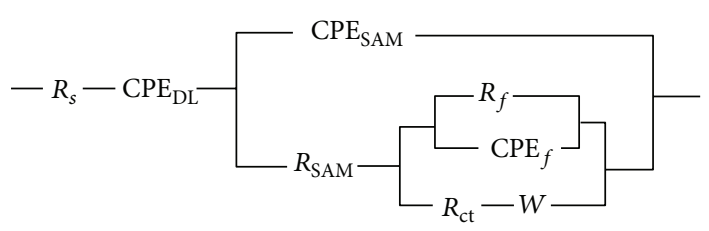

(b)

FIGURE 5: Electric equivalent circuits for the AA7075 samples submitted to different surface modifications: (a) bare surface $\left(\chi^{2}=\right.$ $\left.3.0 e^{-4}\right)$, (b) surface modified with the SAMs $\left(\chi^{2}=5.1 e^{-4}\right)$.

1.0, which quantifies the capacitance dispersion, $\omega=2 \pi f$ is the angular frequency of the harmonic wave, and $i=\sqrt{-1}$. When $n$ approaches 1 , the CPE approaches the pure capacitive behaviour $\left(Y_{0}=\right.$ capacitance $)$.

The capacitance dispersion is associated to different kinds and levels of heterogeneities in the interfacial region. For capacitance dispersion related to the film pseudocapacitive behaviour $\left(\mathrm{CPE}_{f}\right)$, several studies have demonstrated links between dispersion and film morphological characteristics [60-62]. Otherwise, for the electrode/solution interfacial capacitance $\left(\mathrm{CPE}_{\mathrm{DL}}\right)$, the dispersion is related to the heterogeneous dynamics of phase transitions in the interfacial region, as solvent molecules reorientation on the surface [63, 64] and adsorption or reorganization of adsorbed layers [6567], which are processes strongly influenced by the surface topography and energetic heterogeneity.

The observation of the corresponding fitting parameters, tabulated in Table 2, shows that the high values of $R_{\mathrm{ct}}$ and $R_{f}$ are coherent with the absence of corrosion and high oxide layer stability at $\eta=-50 \mathrm{mV}$. Under these conditions, an almost pure capacitive behaviour is observed for the oxide film pseudocapacitance, with $n_{f}$ value very close to 1. This observation suggests the natural oxide layer high homogeneity.

The comparison between the bare and SAMs coated surfaces shows that the coatings considerably affect the system impedance behaviour, changing the equivalent electric circuit that represents the physical-chemical characteristics of the interface. Figure 5(b) shows the new equivalent circuit, and the corresponding fitting parameters numerical values are in Table 2.

The equivalent circuit that fits to the coated surface EIS results comprises circuit elements also observed in the electrical circuit applied to the bare surface (Figure 5(a)), related to the oxide film and to the corrosion reaction, and new elements associated to the SAM coating. The SAM related elements are $R_{\mathrm{SAM}}$ and $\mathrm{CPE}_{\mathrm{SAM}}$, which are, respectively, the resistance associated to the SAM and the CPE associated to the pseudocapacitive behaviour of the organic coating. Additionally, there is a Warburg element $(W)$, related to the diffusion of corroding species to the oxide surface, across the SAM defects.

This equivalent circuit is usually applied to describe the action of organic coatings in corrosion protection. It was originally developed to describe the impedance behaviour of painted surfaces under corrosion, as presented by Walter [55]. In this model the capacitor related to the $\mathrm{DL}\left(C_{\mathrm{DL}}\right)$ is parallel to the capacitor related to the coating capacitive behaviour, while it is in series with the resistance associated to the same coating. This configuration is associated to the fact that corrosion takes place inside the coating defects, so the Randle's subcircuit, show in Figure 5(b), is in series with $R_{\mathrm{SAM}}$, which resembles the coating impedance where its integrity was compromised.

It is possible to note, from Table 2 , that $R_{\mathrm{ct}}$ and $R_{f}$ values for the SAM coated samples suggest that the oxide layer stabilization, promoted by the coating, is the basis of the corrosion protection mechanism. This observation comes from the fact that $R_{f}$ values are higher for the coated samples and, consequently, high values of $R_{\mathrm{ct}}$ are observed. Considering yet this relation between $R_{f}$ and $R_{\mathrm{ct}}$, it is possible to conclude the higher effectiveness of the ODTMS as protective coating.

The main difference between the impedance behaviour for both SAMs is the presence of a Warburg impedance circuit element, related to diffusion-controlled mass transport through SAM, for the ODTMS coating. This characteristic is clearly related to the fact that the ODTMS molecules are considerable longer (18 carbon atoms in the aliphatic chain) than the PTMS ones (3 carbon atoms), which results in a ODTMS coating considerably thicker than the other. Under these conditions, the ODTMS coating hampers the mass transport of the corroding species from the solution to the surface.

\section{Conclusions}

The electrochemical behavior of the ODTMS and PTMS SAM coated AA7075 aluminium alloy has shown the corrosion protection potential of the SAMs. The monolayers at the alloy surface displace the corrosion process to more noble potentials (higher potentials) and partially disable the ORR, as observed on the polarization curves. Complementarily, the impedance behaviour of SAMs has demonstrated the monolayers stability in the potential conditions where they effectively work as corrosion protective coatings, thus suggesting that the corrosion protection comes from the obstruction of the corroding species access to the alloy surface, hence protecting the natural oxide layer integrity.

All the results indicate the ODTMS SAM superior protective behaviour, when compared to the PTMS. This behaviour probably comes from the different size of the molecules that form the SAM, resulting in a higher thickness for the ODTMS monolayer.

Generally, the results indicate the good potentiality of both studied SAMs on the AA7075, indicating that this corrosion protection strategy could be applied to different aluminium alloys. These results are a good starting point for future application of siloxane SAMs to the corrosion protection of the aluminium alloys. 
TABLE 2: Fitting parameters for the equivalent circuits used in this study.

\begin{tabular}{lccc}
\hline Parameter & Bared sample $^{\mathrm{a}}$ & PTMS coating $^{\mathrm{b}}$ & ODTMS coating $^{\mathrm{b}}$ \\
\hline$R_{s}\left(\Omega \mathrm{cm}^{2}\right)$ & 20.8 & 19.3 & 21.0 \\
$R_{\mathrm{ct}}\left(\mathrm{k} \Omega \mathrm{cm}^{2}\right)$ & 1.41 & 1.17 & 6.61 \\
$R_{f}\left(\mathrm{k} \Omega \mathrm{cm}^{2}\right)$ & 0.78 & 1.34 & $4.5 \times 10^{2}$ \\
$R_{\mathrm{SAM}}\left(\mathrm{k} \Omega \mathrm{cm}^{2}\right)$ & - & 1.37 & 0.14 \\
$Y_{0 \mathrm{SAM}}\left(\mathrm{F} /\left(\mathrm{cm}^{2} \mathrm{~s}^{1-n_{\mathrm{SAM}}}\right)\right)$ & - & $3.4 \times 10^{-5}$ & $5.6 \times 10^{-6}$ \\
$n_{\mathrm{SAM}}$ & - & 0.93 & 0.79 \\
$Y_{0 \mathrm{DL}}\left(\mathrm{F} /\left(\mathrm{cm}^{2} \mathrm{~s}^{1-n_{\mathrm{DL}}}\right)\right)$ & $8.5 \times 10^{-4}$ & $5.1 \times 10^{-4}$ & $3.2 \times 10^{-4}$ \\
$n_{\mathrm{DL}}\left(\mathrm{F} /\left(\mathrm{cm}^{2} \mathrm{~s}^{1-n_{f}}\right)\right)$ & $4.1 \times 10^{-4}$ & 1.0 & 1.0 \\
$Y_{0 f}$ & $1.1 \times 10^{-5}$ & $1.0 \times 10^{-6}$ \\
$n_{f}$ & 0.96 & 1.0 & 0.82 \\
$\sigma(\mathrm{W})\left(\mathrm{F} /\left(\mathrm{cm}^{2} \mathrm{~s}^{1 / 2}\right)\right)$ & - & - & $1.6 \times 10^{-3}$ \\
\hline
\end{tabular}

${ }^{\mathrm{a} C i r c u i t}$ on Figure 5(a). ${ }^{\mathrm{b}}$ Circuit on Figure 5(b).

\section{Acknowledgments}

The authors thank the financial support from FAPESP, Brazil (Project 04/12189-1). R. S. Neves also thanks FAPESP for the postdoctoral Grant (Project 06/04122-0).

\section{References}

[1] J. R. Davis, Ed., Corrosion of Aluminium and Aluminium Alloys, ASM International, New York, NY, USA, 1999.

[2] C. Vargel, M. Jacques, and M. P. Schmidt, Corrosion of Aluminium, Elsevier, London, UK, 2004.

[3] G. Bierwagen, "Next generation of aircraft coatings systems," Journal of Coatings Technology, vol. 73, no. 915, pp. 45-52, 2001.

[4] R. Rabicot, R. Brown, and S. C. Yang, "Corrosion protection of aluminum alloys by double-strand polyaniline," Synthetic Metals, vol. 85, no. 1-3, p. 1263, 1997.

[5] F. Andreatta, H. Terryn, and J. H. W. de Wit, "Corrosion behaviour of different tempers of AA7075 aluminium alloy," Electrochimica Acta, vol. 49, no. 17-18, pp. 2851-2862, 2004.

[6] Q. Meng and G. S. Frankel, "Characterization of chromate conversion coating on AA7075-T6 aluminum alloy," Surface and Interface Analysis, vol. 36, no. 1, pp. 30-42, 2004.

[7] K. Jones and D. W. Hoeppner, "Pit-to-crack transition in pre-corroded 7075-T6 aluminum alloy under cyclic loading," Corrosion Science, vol. 47, no. 9, pp. 2185-2198, 2005.

[8] Z. Zhao and G. S. Frankel, "On the first breakdown in AA7075T6," Corrosion Science, vol. 49, no. 7, pp. 3064-3088, 2007.

[9] Z. Zhao and G. S. Frankel, "The effect of temper on the first breakdown in AA7075," Corrosion Science, vol. 49, no. 7, pp. 3089-3111, 2007.

[10] K. H. Na and S. I. Pyun, "Comparison of susceptibility to pitting corrosion of AA2024-T4, AA7075-T651 and AA7475T761 aluminium alloys in neutral chloride solutions using electrochemical noise analysis," Corrosion Science, vol. 50, no. 1, pp. 248-258, 2008.

[11] C. M. Liao and R. P. Wei, "Galvanic coupling of model alloys to aluminum-a foundation for understanding particle-induced pitting in aluminum alloys," Electrochimica Acta, vol. 45, no. 6, pp. 881-888, 1999.

[12] R. J. Jouet, A. D. Warren, D. M. Rosenberg, V. J. Bellitto, K. Park, and M. R. Zachariah, "Surface passivation of bare aluminum nanoparticles using perfluoroalkyl carboxylic acids," Chemistry of Materials, vol. 17, no. 11, pp. 2987-2996, 2005.

[13] P. E. Hintze and L. M. Calle, "Electrochemical properties and corrosion protection of organosilane self-assembled monolayers on aluminum 2024-T3," Electrochimica Acta, vol. 51, no. 8-9, pp. 1761-1766, 2006.

[14] F. M. Reis, H. G. de Melo, and I. Costa, "EIS investigation on Al 5052 alloy surface preparation for self-assembling monolayer," Electrochimica Acta, vol. 51, no. 8-9, pp. 1780-1788, 2006.

[15] V. Palanivel, Y. Huang, and W. J. van Ooij, "Effects of addition of corrosion inhibitors to silane films on the performance of AA2024-T3 in a $0.5 \mathrm{M} \mathrm{NaCl}$ solution," Progress in Organic Coatings, vol. 53, no. 2, pp. 153-168, 2005.

[16] A. Ulman, "Formation and structure of self-assembled monolayers," Chemical Reviews, vol. 96, no. 4, pp. 1533-1554, 1996.

[17] F. Schreiber, "Structure and growth of self-assembling monolayers," Progress in Surface Science, vol. 65, no. 5-8, pp. 151-256, 2000.

[18] R. K. Smith, P. A. Lewis, and P. S. Weiss, "Patterning selfassembled monolayers," Progress in Surface Science, vol. 75, no. 1-2, 2004.

[19] J. G. van Alsten, "Self-assembled monolayers on engineering metals: structure, derivatization, and utility," Langmuir, vol. 15, no. 22, pp. 7605-7614, 1999.

[20] Y. Yamamoto, H. Nishihara, and K. Aramaki, "Self-assembled layers of alkanethiols on copper for protection against corrosion," Journal of the Electrochemical Society, vol. 140, no. 2, pp. 436-443, 1993.

[21] G. K. Jennings and P. E. Laibinis, "Self-assembled monolayers of alkanethiols on copper provide corrosion resistance in aqueous environments," Colloids and Surfaces A: Physicochemical and Engineering Aspects, vol. 116, no. 1-2, pp. 105-114, 1996.

[22] G. K. Jennings, J. C. Munro, T. H. Yong, and P. E. Laibinis, "Effect of chain length on the protection of copper by n-alkanethiols," Langmuir, vol. 14, no. 21, pp. 6130-6139, 1998.

[23] G. K. Jennings, J. C. Munro, and P. E. Laibinis, "Effects of film crystallinity on the protective properties of self-assembled monolayers of alkanethiols on copper," Advanced Materials, vol. 11, no. 12, pp. 1000-1003, 1999.

[24] E. Hoque, J. A. DeRose, R. Houriet, P. Hoffmann, and H. J. Mathieu, "Stable perfluorosilane self-assembled monolayers on copper oxide surfaces: evidence of siloxy-copper bond 
formation," Chemistry of Materials, vol. 19, no. 4, pp. 798-804, 2007.

[25] F. Sinapi, I. Lejeune, J. Delhalle, and Z. Mekhalif, "Comparative protective abilities of organothiols SAM coatings applied to copper dissolution in aqueous environments," Electrochimica Acta, vol. 52, no. 16, pp. 5182-5190, 2007.

[26] F. Sinapi, S. Julien, D. Auguste, L. Hevesi, J. Delhalle, and Z. Mekhalif, "Monolayers and mixed-layers on copper towards corrosion protection," Electrochimica Acta, vol. 53, no. 12, pp. 4228-4238, 2008.

[27] F. Deflorian, S. Rossi, and L. Fedrizzi, "Silane pre-treatments on copper and aluminium," Electrochimica Acta, vol. 51, no. 27, pp. 6097-6103, 2006.

[28] K. Nozawa, H. Nishihara, and K. Aramaki, "Chemical modification of alkanethiol monolayers for protecting iron against corrosion," Corrosion Science, vol. 39, no. 9, pp. 1625-1639, 1997.

[29] K. Nozawa and K. Aramaki, "One- and two-dimensional polymer films of modified alkanethiol monolayers for preventing iron from corrosion," Corrosion Science, vol. 41, no. 1, pp. 57-73, 1999.

[30] K. Aramaki and T. Shimura, "Complete protection of a passive film on iron from breakdown in a borate buffer containing 0.1 $\mathrm{M}$ of Cl- by coverage with an ultrathin film of two-dimensional polymer," Corrosion Science, vol. 48, no. 1, pp. 209-225, 2006.

[31] I. L. Liakos, R. C. Newman, E. McAlpine, and M. R. Alexander, "Study of the resistance of SAMs on aluminium to acidic and basic solutions using dynamic contact angle measurement," Langmuir, vol. 23, no. 3, pp. 995-999, 2007.

[32] J. B. Bajat, I. Milosev, Z. Jovanovic, R. M. Jancic-Heinemann, M. Dimitrijevic, and V. B. Miskovic-Stankovic, "Corrosion protection of aluminium pretreated by vinyltriethoxysilane in sodium chloride solution," Corrosion Science, vol. 52, no. 3, pp. 1060-1069, 2010.

[33] L. M. Palomino, P. H. Suegama, I. V. Aoki, M. Fatima Montemor, and H. G. de Melo, "Electrochemical study of modified nonfunctional bis-silane layers on Al alloy 2024-T3," Corrosion Science, vol. 50, no. 5, pp. 1258-1266, 2008.

[34] A. Frignani, F. Zucchi, G. Trabanelli, and V. Grassi, "Protective action towards aluminium corrosion by silanes with a long aliphatic chain," Corrosion Science, vol. 48, no. 8, pp. 2258-2273, 2006.

[35] I. de Graeve, J. Vereecken, A. Franquet, T. van Schaftinghen, and H. Terryn, "Silane coating of metal substrates: complementary use of electrochemical, optical and thermal analysis for the evaluation of film properties," Progress in Organic Coatings, vol. 59, no. 3, pp. 224-229, 2007.

[36] F. P. Zamborini and R. M. Crooks, "Corrosion passivation of gold by n-alkanethiol self-assembled monolayers: effect of chain length and end group," Langmuir, vol. 14, no. 12, pp. 3279-3286, 1998.

[37] I. Maege, E. Jaehne, A. Henke et al., "Self-assembling adhesion promoters for corrosion resistant metal polymer interfaces," Progress in Organic Coatings, vol. 34, no. 1-4, pp. 1-12, 1997.

[38] L. Cecchetto, A. Denoyelle, D. Delabouglise, and J. P. Petit, "A silane pre-treatment for improving corrosion resistance performances of emeraldine base-coated aluminium samples in neutral environment," Applied Surface Science, vol. 254, no. 6, pp. 1736-1743, 2008.

[39] Z. F. Li and E. Ruckenstein, "Strong adhesion and smooth conductive surface via graft polymerization of aniline on a modified glass fiber surface," Journal of Colloid and Interface Science, vol. 251, no. 2, pp. 343-349, 2002.
[40] D. P. B. Silva, R. S. Neves, and A. J. Motheo, "Corrosion protection of aluminum alloys by methoxy-silanes(SAM)/polyaniline double films," ECS Transactions, vol. 43, no. 1, pp. 57-64, 2012.

[41] D. P. B. Silva, R. S. Neves, and A. J. Motheo, "Electrochemical behaviour of the AA2024 aluminium alloy modified with selfassembled monolayers/polyaniline double films," Molecular Crystals and Liquid Crystals, vol. 521, pp. 179-186, 2010.

[42] E. Ruckenstein and Z. F. Li, "Surface modification and functionalization through the self-assembled monolayer and graft polymerization," Advances in Colloid and Interface Science, vol. 113, no. 1, pp. 43-63, 2005.

[43] Z. F. Li and E. Ruckenstein, "Conductive surface via graft polymerization of aniline on a modified glass surface," Synthetic Metals, vol. 129, no. 1, pp. 73-83, 2002.

[44] L. Thomsen, B. Watts, D. V. Cotton, J. S. Quinton, and P. C. Dastoor, "Adsorption and orientation kinetics of self-assembled films of octadecyltrimethoxysilane on aluminium oxide surfaces," Surface and Interface Analysis, vol. 37, no. 5, pp. 472-477, 2005.

[45] C. P. Tripp and M. L. Hair, "Direct observation of the surface bonds between self-assembled monolayers of octadecyltrichlorosilane and silica surfaces: a low-frequency IR study at the solid/liquid interface," Langmuir, vol. 11, no. 4, pp. 1215-1219, 1995.

[46] C. P. Tripp and M. L. Hair, "Reaction of methylsilanols with hydrated silica surfaces: the hydrolysis of trichloro-, dichloro, and monochloromethylsilanes and the effects of curing," Langmuir, vol. 11, no. 1, pp. 149-155, 1995.

[47] D. Devaprakasam, S. Sampath, and S. K. Biswas, "Thermal stability of perfluoroalkyl silane self-assembled on a polycrystalline aluminum surface," Langmuir, vol. 20, no. 4, pp. 13291334, 2004.

[48] J. Quinton, L. Thomsen, and P. Dastoor, "Adsorption of organosilanes on iron and aluminium oxide surfaces," Surface and Interface Analysis, vol. 25, no. 12, pp. 931-936, 1997.

[49] J. Quinton, P. Dastoor, and W. Allison, "PTMS on iron and aluminium oxide surfaces: a study of damped adsorption kinetics," Surface Science, vol. 402-404, pp. 66-70, 1998.

[50] J. S. Quinton and P. C. Dastoor, "Effect of experimental conditions on the oscillatory adsorption of propyltrimethoxysilane on aluminum oxide surfaces," Applied Surface Science, vol. 152, no. 3, pp. 131-137, 1999.

[51] J. S. Quinton and P. C. Dastoor, "Influence of surface electrokinetics on organosilane adsorption," Surface and Interface Analysis, vol. 28, no. 1, pp. 12-15, 1999.

[52] J. S. Quinton and P. C. Dastoor, "Conformational dynamics of $\gamma$-APS on the iron oxide surface: an adsorption kinetic study using XPS and ToF-SIMS," Surface and Interface Analysis, vol. 30, no. 1, pp. 21-24, 2000.

[53] B. Watts, L. Thomsen, J. R. Fabien, and P. C. Dastoor, "Understanding the conformational dynamics of organosilanes: $\gamma$-APS on zinc oxide surfaces," Langmuir, vol. 18, no. 1, pp. 148-154, 2002.

[54] B. A. Boukamp, EQUIVCRT, Computer Software for Analysis of Impedance Data, Techinical University of Twente, Enschede, The Netherlands, 1989.

[55] G. W. Walter, "A review of impedance plot methods used for corrosion performance analysis of painted metals," Corrosion Science, vol. 26, no. 9, pp. 681-703, 1986.

[56] K. Jüttner, "Electrochemical impedance spectroscopy (EIS) of corrosion processes on inhomogeneous surfaces," Electrochimica Acta, vol. 35, no. 10, pp. 1501-1508, 1990. 
[57] T. Tüken, B. Yazici, and M. Erbil, "The corrosion behaviour of polypyrrole coating synthesized in phenylphosphonic acid solution," Applied Surface Science, vol. 252, no. 6, pp. 2311-2318, 2006.

[58] R. de Levie, "On porous electrodes in electrolyte solutions-IV," Electrochimica Acta, vol. 9, no. 9, pp. 1231-1245, 1964.

[59] G. J. Brug, A. L. G. van den Eeden, M. Sluyters-Rehbach, and J. H. Sluyters, "The analysis of electrode impedances complicated by the presence of a constant phase element," Journal of Electroanalytical Chemistry, vol. 176, no. 1-2, pp. 275-295, 1984.

[60] J. Bisquert, G. Garcia-Belmonte, F. Fabregat-Santiago, and A. Compte, "Anomalous transport effects in the impedance of porous film electrodes," Electrochemistry Communications, vol. 1, no. 9, pp. 429-435, 1999.

[61] E. de Robertis, R. S. Neves, L. M. Abrantes, and A. J. Motheo, "Pd-P electroless deposition on carbon steel: an electrochemical impedance spectroscopy study," Journal of Electroanalytical Chemistry, vol. 581, no. 1, pp. 86-92, 2005.

[62] G. R. P. Malpass, R. S. Neves, and A. J. Motheo, "A comparative study of commercial and laboratory-made Ti/Ru0.3Ti0.7O2 DSA electrodes: "In situ" and "ex situ" surface characterisation and organic oxidation activity," Electrochimica Acta, vol. 52, no. 3, pp. 936-944, 2006.

[63] A. J. Motheo, A. Sadkowski, and R. S. Neves, "Electrochemical immittance spectroscopy applied to the study of the single crystal gold/aqueous perchloric acid interface," Journal of Electroanalytical Chemistry, vol. 430, no. 1-2, pp. 253-262, 1997.

[64] A. Sadkowski, A. J. Motheo, and R. S. Neves, "Characterisation of $\mathrm{Au}(111)$ and $\mathrm{Au}(210)$ aqueous solution interfaces by electrochemical immittance spectroscopy," Journal of Electroanalytical Chemistry, vol. 455, no. 1-2, pp. 107-119, 1998.

[65] T. Pajkossy, T. Wandlowski, and D. M. Kolb, "Impedance aspects of anion adsorption on gold single crystal electrodes," Journal of Electroanalytical Chemistry, vol. 414, no. 2, pp. 209-220, 1996.

[66] R. S. Neves, E. de Robertis, and A. J. Motheo, "Capacitance dispersion in EIS measurements of halides adsorption on $\mathrm{Au}(2$ $10)$," Electrochimica Acta, vol. 51, no. 7, pp. 1215-1224, 2006.

[67] R. S. Neves, E. de Robertis, and A. J. Motheo, "Capacitance dispersion in electrochemical impedance spectroscopy measurements of iodide adsorption on Au(1 11 1)," Applied Surface Science, vol. 253, no. 3, pp. 1379-1386, 2006. 


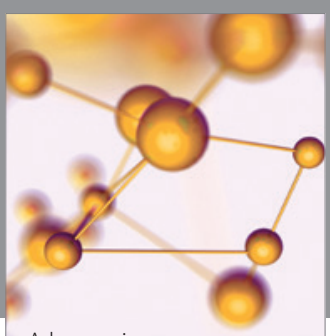

Physical Chemistry
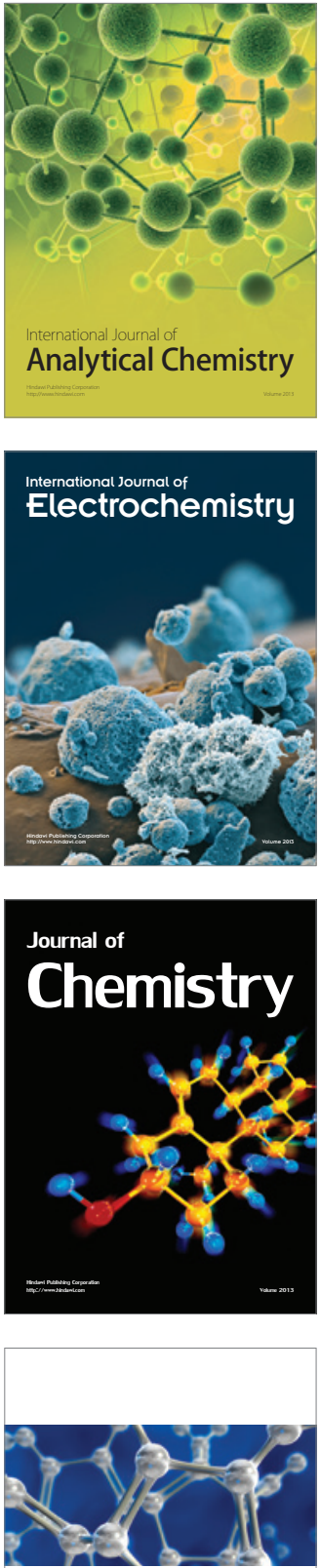

ISRN

Inorganic Chemistry

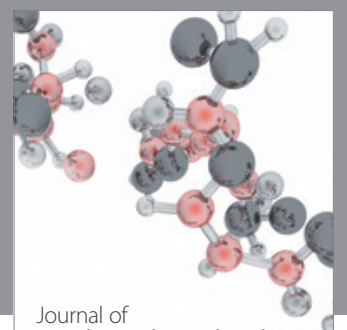

Analytical Methods in Chemistry

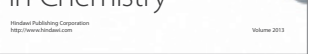

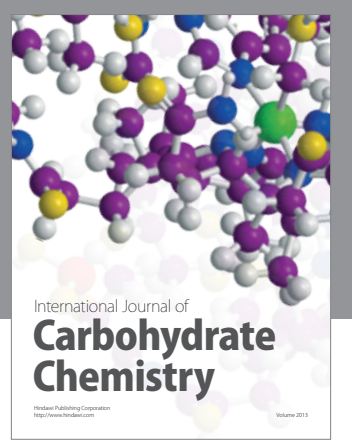
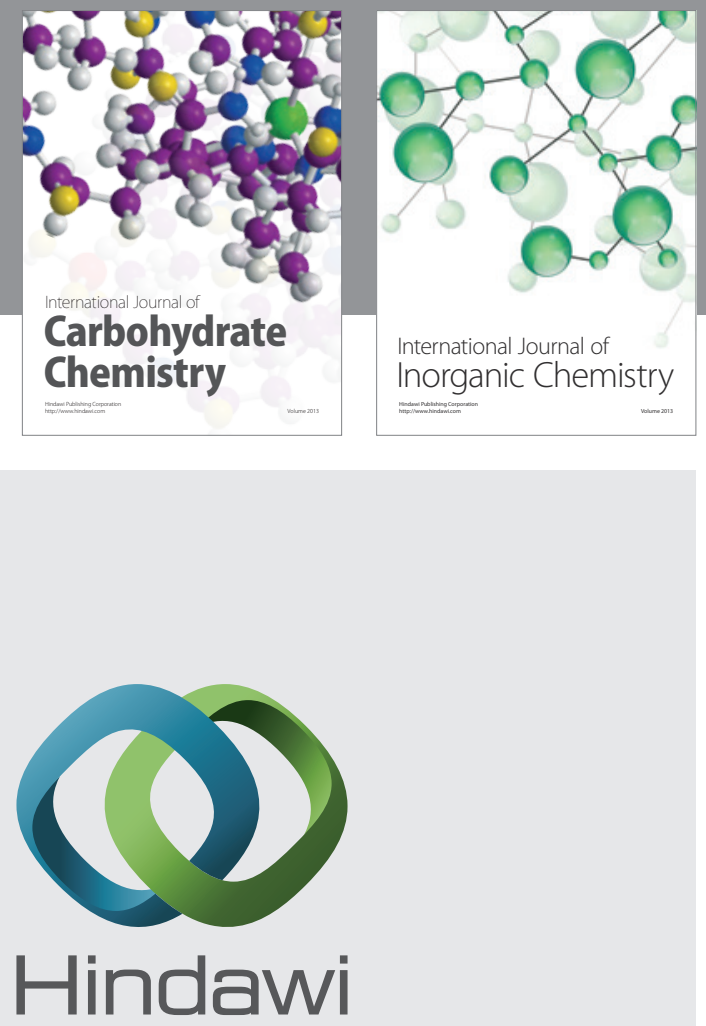

Submit your manuscripts at http://www.hindawi.com
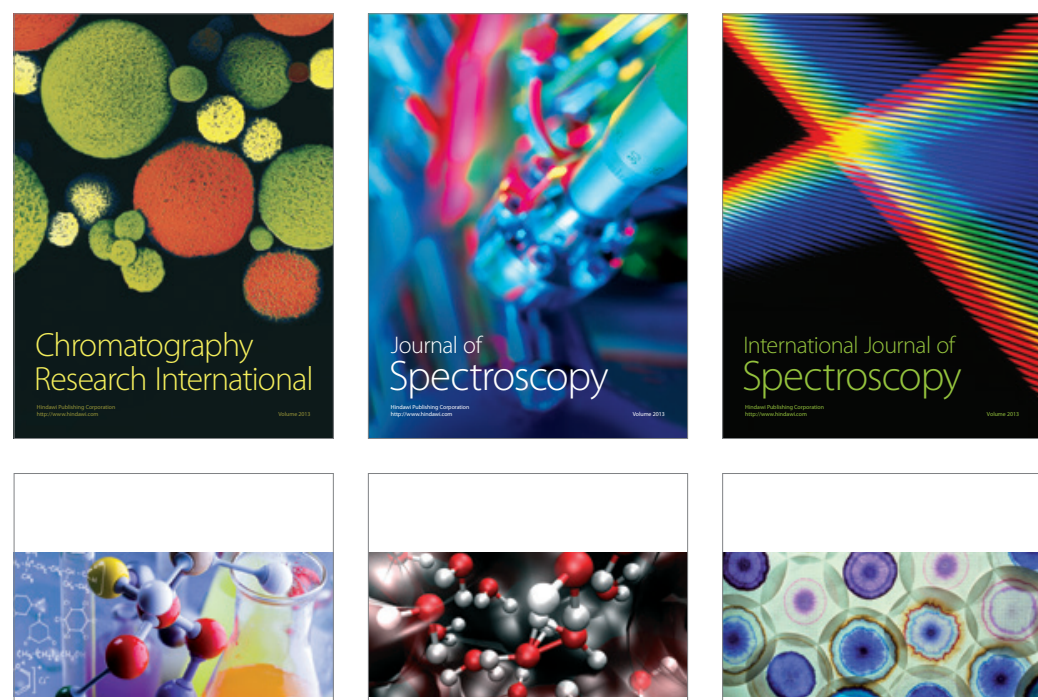

ISRN

ISRN

Organic Chemistry

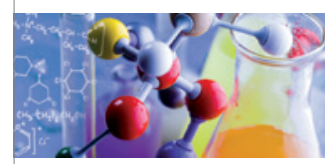

Physical Chemistry

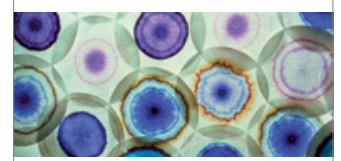

ISRN

Chromatography

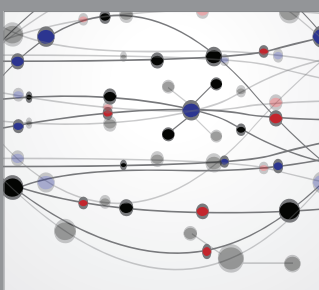

The Scientific World Journal
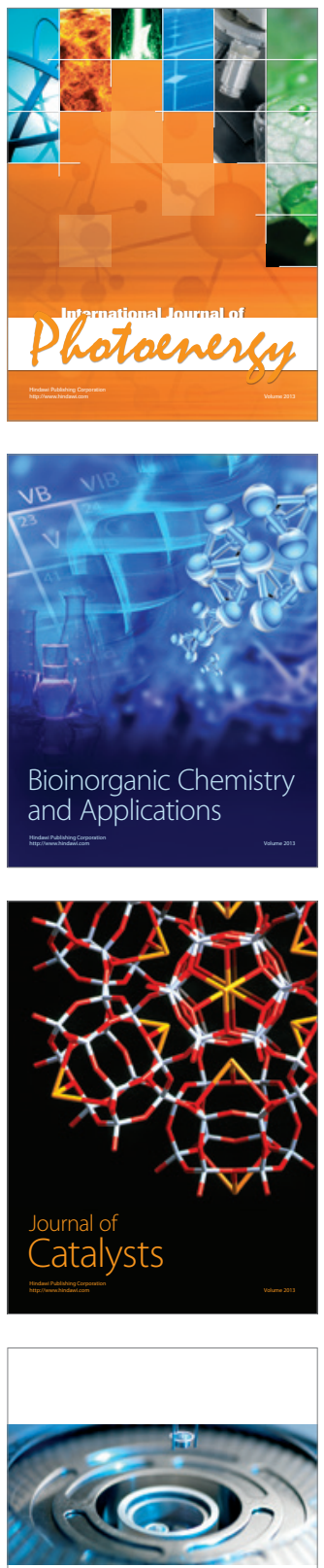

ISRN

Analytical

Chemistry 


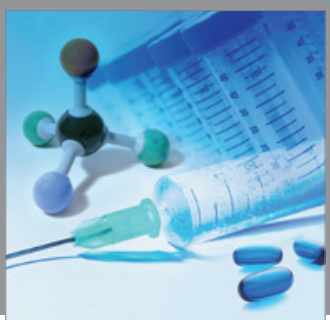

International Journal of

Medicinal Chemistry

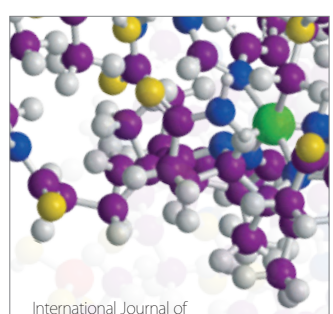

Carbohydrate Chemistry

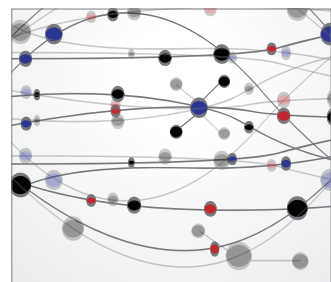

The Scientific World Journal
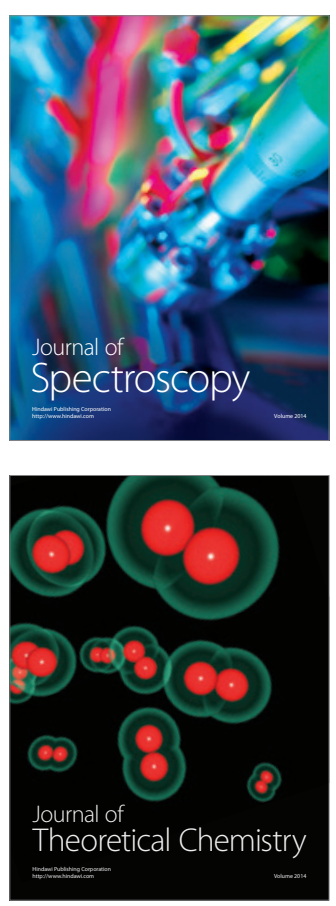
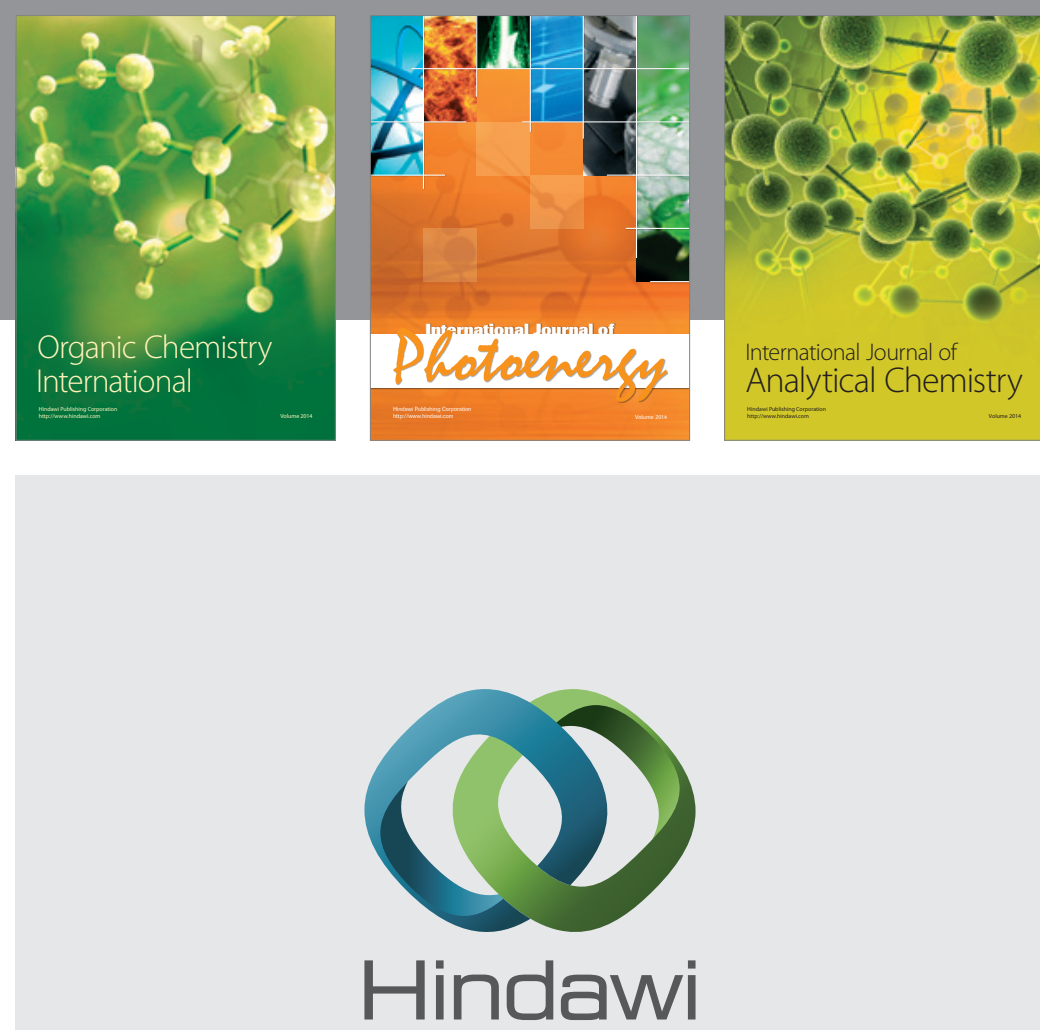

Submit your manuscripts at

http://www.hindawi.com
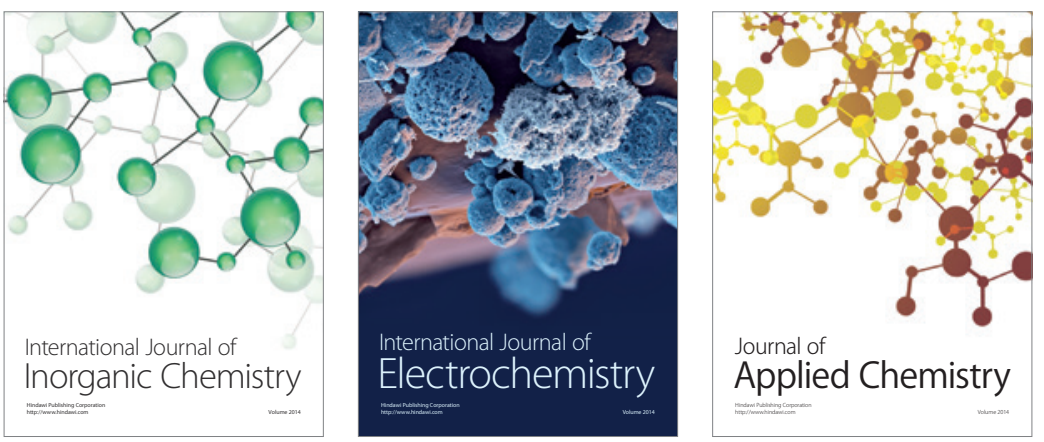

Journal of

Applied Chemistry
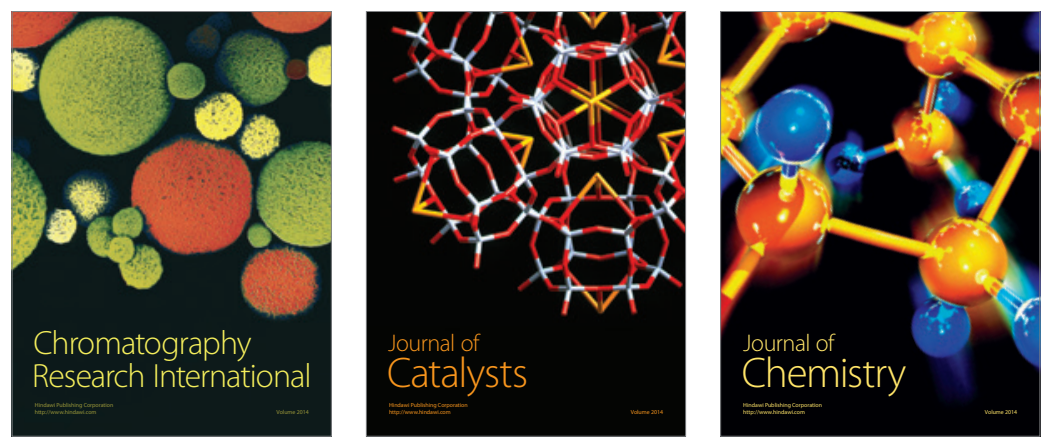
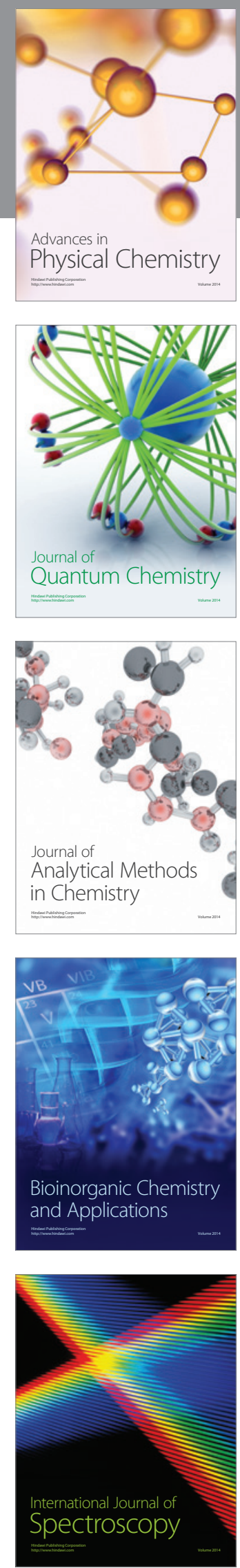